\title{
PRE-ANALYSIS PLAN FOR The Elasticity of TAX COMPLIANCE: EVIDENCE FROM RANDOMIZED PROPERTY TAX RATES ${ }^{\dagger}$
}

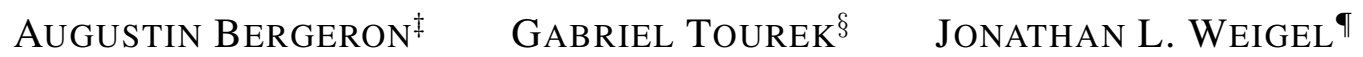

January 24,2019

\begin{abstract}
How does tax compliance vary with the size of the tax burden when opportunities for evasion are high? This paper estimates the elasticity of property tax compliance in a field experiment in Kananga, the Democratic Republic of Congo, a setting where the status quo level of compliance is low. In collaboration with the provincial government, we randomly assign four fixed tax rates at the household level as part of a door-to-door city-wide tax collection campaign. Individuals face between 50 and $100 \%$ of their true liability. We study how compliance and total government revenues vary with the rate. We also examine the effects of randomized rates on bribe payment and contributions to informal taxes (in-kind labor payments). Our findings will contribute to knowledge about the determinants of tax compliance in weak states as well as the design of optimal liabilities and enforcement in such settings.
\end{abstract}

\footnotetext{
${ }^{\dagger}$ This study has been approved by the Harvard Institutional Review Board (Protocol IRB17-0724) and is funded by the J-PAL Governance Initiative.

${ }^{\ddagger}$ Department of Economics, Harvard University augustinbergeron@fas.harvard.edu

${ }^{\S}$ Harvard Kennedy School gabrieltourek@g.harvard.edu

`Department of International Development, London School of Economics and Political Science j.weigel@1se.ac.uk
} 


\section{Introduction}

A rudimentary level of state capacity is thought to be a precondition for economic development (Huntington, 2006; Besley and Persson, 2009). Tax capacity, in particular, enables states to provide public goods and is associated with more accountable, responsive governance (Kaldor, 1963; Moore, 2008; Pritchard, 2015). But the transition to becoming a 'tax state' is perhaps the greatest challenge of state building (Schumpeter, 1918). Many states are caught in a low-capacity trap: the state has insufficient revenue to provide public goods, and citizens refuse to pay taxes until the state provides public goods. How can low-capacity states escape this trap?

In our setting, the Democratic Republic of the Congo (DRC), the state is weak and has low tax revenues, especially at the provincial level. With a population of some 6 million people, the total revenues of the Provincial Government of Kasai Occidental from 2010-2015 were around \$2 million per year, less than $\$ 0.30$ per person per year. The great majority of these revenues comes from mineral rents and gatekeeper-style transport fees. When surveyed in early 2016, fewer than 3\% of households in the capital city of Kananga reported ever having paid property taxes. In a previous experiment in Kananga, tax collectors were sent to randomly selected neighborhoods in the city to boost property tax revenues (Weigel, 2018). The program caused a 10 percentage point increase in property tax payment. Nonetheless, nearly $90 \%$ of households — almost all of which were visited by tax collectors — still refused tax payment. Since less than $1 \%$ appear to have paid bribes instead of the tax, the vast majority of citizens are simply non-compliant.

Although a growing number of empirical papers consider tax compliance in both developed (Blumenthal, Christian, Slemrod, and Smith, 2001; Fellner, Sausgruber, and Traxler, 2013; Hallsworth, List, Metcalfe, and Vlaev, 2017) and developing countries (Del Carpio, 2013; Pomeranz, 2015; Dunning, Monestier, Piñeiro, Rosenblatt, and Tuñón, 2015; Bergolo, Ceni, Cruces, Giaccobasso, and PerezTruglia, 2018) a first-order research question has received scant attention to date: what is the elasticity of tax compliance with respect to the tax rate? The public finance literature has a long history of studying the optimal tax schedule with respect to labor supply (Ashenfelter and Plant, 1990; Eissa and Liebman, 1996; Saez, 2010; Chetty, Guren, Manoli, and Weber, 2013) and taxable income elasticities (see Saez, Slemrod, and Giertz (2012) for a review). ${ }^{1}$ However, in many developing countries, tax evasion or refusal to pay taxes are the relevant margins given the low baseline rate of compliance.

This study provides experimental evidence on the effect of the tax rate on compliance in the context of a door-to-door property tax campaign in Kananga, DRC. In partnership with the Provincial Government of Kasai Central, we introduce random variation in tax rates to measure the elasticity of compliance with respect to the financial burden of the tax. Our findings will shed light on the determinants of tax compliance and the design of revenue-optimal rates in settings where state capacity is

\footnotetext{
${ }^{1}$ Moreover, in political science, compliance is often treated as exogenous to revenue creation. See, for example, the concept of 'quasi-voluntary compliance' in Levi (1988).
} 
low. ${ }^{2}$ The tax interventions began in July 2017 and will conclude in December 2018. The timeline for all components of the study can be seen in section 3. Data collection is expected to conclude in April 2019.

\section{Research Questions}

This study seeks to answer several questions related to tax compliance.

- What is the elasticity of the property tax compliance to the size of tax burden in a low-capacity, low-compliance setting?

- What is the elasticity of bribes and informal taxation to the size of the tax burden?

- Do these elasticities vary heterogeneously by individual characteristics?

\section{Interventions}

This study seeks to examine the elasticity of tax compliance with respect to the tax rate. Building on past collaborations with the Provincial Government of Kasai Central, we vary the property tax rate on the household level. Although tax compliance is the principal outcome, we also study effects of randomized tax rates on other outcomes like bribe payment and contributions to informal taxes. To control for potential bias in estimating effects across tax rates introduced by differential effort on the part of tax collectors, we randomly vary their compensation ('bonuses').

This evaluation will occur as a part of a larger property tax campaign that compares two models of tax collection - sending tax ministry staff door to door, or charging local bureaucrats with this responsibility - in terms of revenue generation, leakage, and citizen satisfaction (Balán, Bergeron, Tourek, and Weigel, 2018).

\subsection{Randomly Assigned Tax Rates}

As the first step in a citywide property-tax campaign, collectors randomly distribute tax bills that vary households' tax liability. ${ }^{3}$ The assigned rate depends on the property type, classified as periphery, midrange, or villa. Periphery properties contain small household buildings and are the most common type, accounting for approximately $90 \%$ of properties in Kananga. These properties face a fixed tax rate of 3,000 CF (roughly USD \$2). Midrange houses are larger household buildings that account for

\footnotetext{
${ }^{2}$ This is similar in spirit to Sequeira (2016), who estimates the elasticity of reporting goods to the customs authority in Mozambique and finds that reducing tariffs increases the reported quantities and reduces corruption.

${ }^{3}$ Distribution of tax bills is overseen by independent Congolese enumerators to ensure that tax collectors do not deviate from the randomized order of the tax bills.
} 
approximately $9 \%$ of all properties and face a fixed rate of 13,200 CF (roughly USD \$9). A final type, capturing the remainder, is villas (large estates), for which the tax rate is assessed based on the size of buildings on the property with a median tax amount of USD \$50. Simplified property tax instruments like this have been used historically in developed countries and are common in developing countries today. ${ }^{4}$

In collaboration with the government, we experimentally vary the rate faced by periphery and midrange properties between $50 \%$ and $100 \%$ of the full rate. For periphery properties, the rate varies between 1,500 Congolese Francs (CF) and 3,000 CF, in increments of $500 \mathrm{CF}$. Figure 1 shows a sample tax bill for a periphery property. For midrange properties, the rate varies between $6,600 \mathrm{CF}$ and $13,200 \mathrm{CF}$, in increments of 2,200 CF. Table 1 shows the rates by property type and tax rate. ${ }^{5}$ The 2016 property tax campaign used a fixed levy of 3,000 CF for periphery properties, and average compliance in neighborhoods that received the program was $10 \% .{ }^{6}$ Thus, the government judged that varying the tax rate between the full rate and lower values (for both periphery and midrange properties) would have more substantial effects on the probability of payment than would increasing the tax rate above the true rate. Effectively discounting the official rate for certain households also provides benefits to recipients rather than imposing additional costs relative to their status quo tax obligations. However, citizens are not informed that they may be receiving discounts: they are simply randomly assigned the rate on the tax bill without mention of the full 3,000 FC rate (unless they are assigned that particular rate). Citizens only learn of their assigned rate to avoid perceptions of unfairness or transaction value from influencing their response. We take several steps, as noted below, to measure awareness of others' rates and control for this in our estimations.

\footnotetext{
${ }^{4}$ For instance, the United Kingdom introduced a flat charge (the Community Charge or 'Poll Tax') between 1989 and 1993; Ireland also had a flat rate charge (Household Charge and Residence Charge) until the implementation of the local property tax in 2013. In developing countries, several major Indian cities (e.g. New Delhi, Bangalore, Kolkata) adopted flat rates by unit-area category in 2008. In Tanzania, all properties that are not included on the valuation roll are liable for flat rates. In Sierra Leone, Liberia, and Malawi, the overall tax simplification agenda implies piloting flat rates for properties not on the valuation roll.

${ }^{5}$ For villas, the rate does not vary, as these comprise a small share of overall properties, and the determination of villa rates depends on many inputs that entail visits by experienced tax collectors. Tax collectors involved in the campaign will distribute special tax bills to villa properties and pass the location of villas to the tax authority for special visits. Villas will be excluded from our analysis.

${ }^{6}$ The nominal rate in 2016 was $2,000 \mathrm{CF}$, which is approximately equivalent to 3,000 CF in real terms at the time of this study in 2018.
} 
Table 1: Tax Rate Treatment Groups

\begin{tabular}{ccc}
\hline & \multicolumn{2}{c}{ Rates by Property Type (CF) } \\
\cline { 2 - 3 } \% Full Rate & Periphery & Midrange \\
\hline $100 \%$ & 3,000 & 13,200 \\
$88 \%$ & 2,500 & 11,000 \\
$66 \%$ & 2,000 & 8,800 \\
$50 \%$ & 1,500 & 6,600 \\
\hline
\end{tabular}

Tax collectors distribute and read aloud the tax bills during the census stage of the campaign (described in Section 5.2). The tax bills are printed one one side in French (spoken by everyone with some schooling) and on the other in Tshiluba (the most widely spoken local language).

Finally, there is one last cross-randomized element of the tax bills: on randomly selected tax bills a picture of an example receipt appears along with a phrase noting that the payer should receive a printed receipt. On other tax bills, there is no copy of the receipt nor mention of the printed receipts. We will use this treatment to measure whether information about the receipts enables citizens to hold tax collectors accountable to following the protocol of the campaign, including the issuance of printed receipts, as a means to reduce corruption. ${ }^{7}$

\footnotetext{
${ }^{7}$ As part of the Balán, Bergeron, Tourek, and Weigel (2018) study, we additionally randomize information treatments within the tax bills. In the main elasticity analysis we will control for the message type. We will assess heterogeneous responses to message type as part of the subgroup analysis detailed in Section 4.2
} 
Figure 1: Sample Tax Bill - 3,000 CF Rate

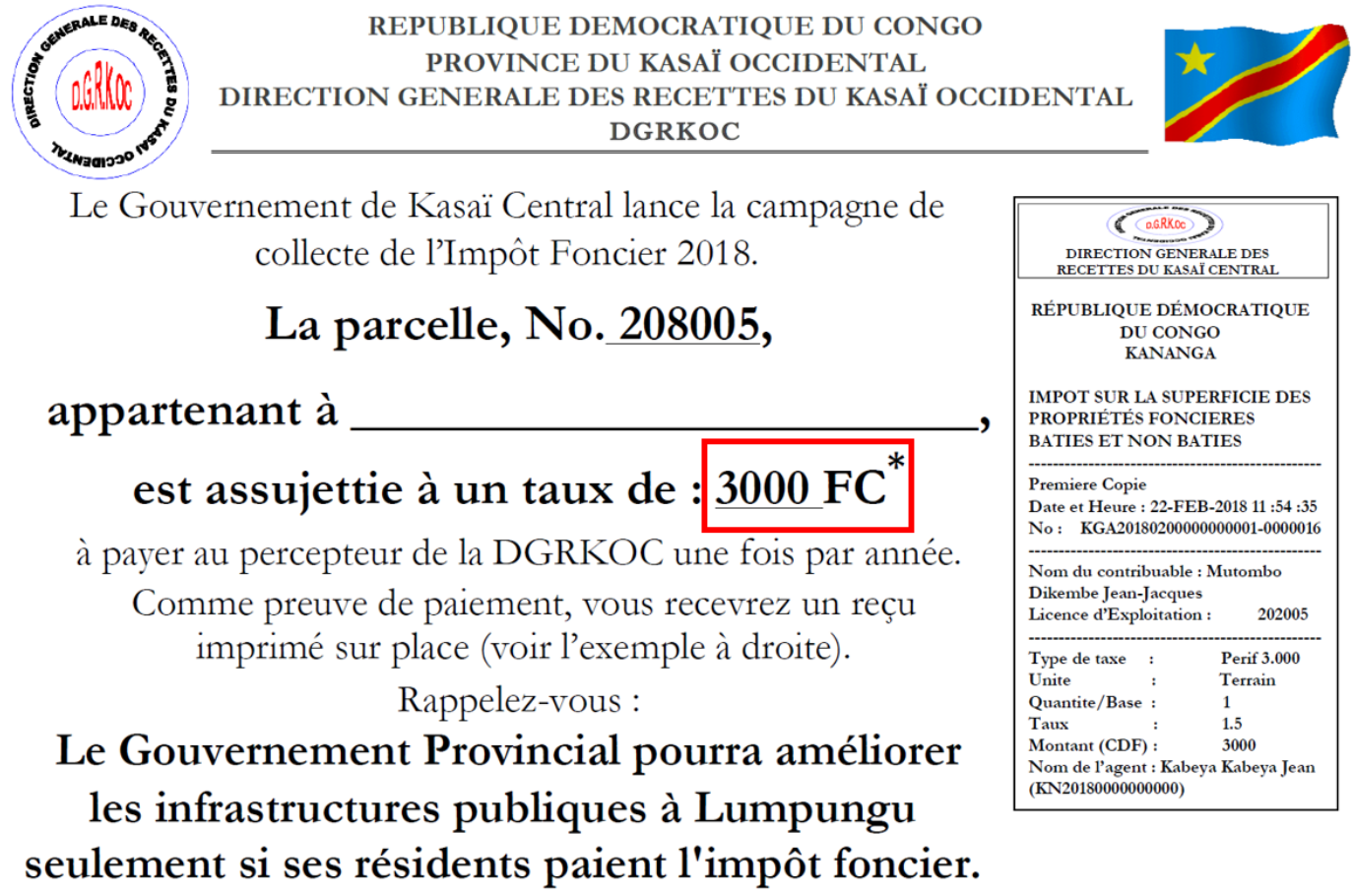

\subsection{Randomly Assigned Bonuses for Tax Collectors}

Following standard tax ministry protocol, tax collectors receive performance-based compensation. Typically, collectors receipt 'bonuses' in proportion to the tax they deposit to the state account. However, a concern is that bonuses of varying amounts assigned to distinct tax rates could produce differential effort in collection. Collectors may target households that offer higher bonuses, and their greater effort could bias the estimated elasticity of compliance.

To address this concern, we randomize bonuses at the household level. Half of the houses in the base category are assigned a fixed $750 \mathrm{CF}$ bonus, and the other half a rate equivalent to $30 \%$ of the rate corresponding to that household. Holding the bonus constant - at a fixed amount or proportional share of the tax amount - will permit us to control for tax collector incentives across rates.

If collectors tax a household during the census, the bonus is constant (750 CF), in order to reduce the temptation to game the randomized order of tax bills. For midrange houses, the bonus is a flat amount of 2,000 CF per house. ${ }^{8}$ Table 2 shows the bonus treatment groups and bonus amounts by property type and tax rate. Bonuses during collection periods will be paid to tax collectors at the end of

\footnotetext{
${ }^{8}$ For the 'villa' category the bonus is $5,000 \mathrm{CF}$ if the villa pays less than or equal to 50 USD and $10,000 \mathrm{CF}$ if it pays more than that amount.
} 
every week; bonuses for collections during the census will be paid immediately by enumerators.

Table 2: Bonus Treatment Groups

\begin{tabular}{lccc}
\hline Property Type & Tax Rate (CF) & $\begin{array}{c}\mathbf{3 0 \%} \\
\text { Bonus (CF) }\end{array}$ & $\begin{array}{c}\text { Constant } \\
\text { Bonus (CF) }\end{array}$ \\
\hline Periphery & 1,500 & 450 & 750 \\
& 2,000 & 600 & 750 \\
& 2,500 & 750 & 750 \\
Midrange house & 3,000 & 900 & 750 \\
\hline
\end{tabular}

\section{Outcomes}

As the focus of the experiment is to estimate the elasticity of compliance and total revenues with respect to the tax rate, the primary outcome of interest is tax payment. We will measure payment using administrative data from the tax campaign. We additionally compare this to self-reported measures of payment by property owners. We will also measure other outcomes relevant to the estimation of the elasticity. These include visits by the tax collector (self-reported by the property owner), to control for effort on the part of the collector and to study how differences in tax rates may shape collector effort itself. We will also collect self-reported measures of the existence and amounts of bribes solicited by or paid to tax collectors, which will allow us to estimate an elasticity of corruption to the tax rate. Finally, we will collect outcomes measuring households' contributions to informal taxes (e.g., Salongo ${ }^{9}$ ).

\subsection{Outcomes}

1. Compliance with property tax obligations (defined as a binary outcome for whether an individual property owner paid property taxes, receipt-logged or reported by the owner, or a receipt-logged amount of payment and self-reported payment amount for individual property owners which may differ from the assigned rate amount due to collector error, collector willingness to accept a lower rate, or corruption): We expect higher compliance at lower rates

2. Visits by tax collector (defined as a binary outcome for whether an individual property owner was visited by a tax collector as reported by the owner and a continuous measure of visits to property for purpose of tax collection by tax collectors, as reported by property owner): The relationship between visits and the tax rate is ambiguous as it depends on how the difficulty of collection

\footnotetext{
${ }^{9}$ Salongo is a local informal tax in which citizens contribute time or money to collective community projects organized by local chiefs. We will consider Salongo and other informal contributions to public goods or payments to government officials as informal taxes, following Olken and Singhal (2011)
} 
varies with the assigned rate - collectors may visit households assigned higher rates more often, as the average bonus assigned to those households is higher (as a function of the proportional-torate bonus being assigned to $50 \%$ of households); however, collectors may also visit lower-rate households because they find that it is easier to convince individuals to pay lower amounts after repeat interactions, while those assigned higher rates are much less likely to pay even with repeat visits.

3. Bribe paid (defined as self-reported payment and amount of bribe paid by individual property owners to a tax collector $)^{10}$ : The relationship between bribes and rate is ambiguous. Bribes may go down when rate goes down, because the bribe bargaining power of the collector is a function of tax amount (outside option is to collect the full rate) which decreases when tax goes down. However, it may also be possible that tax collectors ask for bribes more often and succeed more often when the tax rate is low - e.g. if tax collectors threaten lower-rate households with higher rates and agree to collect the low rate only if they are given a bribe.

4. Contributions to informal taxes (including participation in Salongo - defined as self-reports by property owners of whether they participated in a weekly public goods institution, organized at the neighborhood level of local chiefs, in which citizens contribute time or money to collective community projects; we will also have an intensive margin measure, counting the number of hours devoted to Salongo in the past weeks): The relationship between these contributions and the tax rate is ambiguous. For people who pay taxes, it depends on whether such contributions and taxes are complements or substitutes - e.g., payers may feel relieved of the duty to participate in Salongo if they paid the tax, or may feel that because they paid they deserve to take a more active role in directing the focus of the Salongo work by participating more. For people who do not pay the tax, the prediction is also ambiguous. Those assigned lower rates may believe collections at low rates are unlikely to yield sufficient state resources to provide public goods, motivating them to contribute to informal non-state goods. However, they may also believe that, at low rates, everyone will pay taxes so collections will be high and sufficient to provide public goods and therefore may choose to reduce contributions to informal taxes that would provide those goods in the absence of state provision.

5. Measures of spending and consumption (including school fees, health expenditures, contributions to church, and property investments, as spending that could be crowded out by tax payments): We expect spending and consumption of other goods and services to decrease with the rate due to crowd out.

\footnotetext{
${ }^{10}$ Bribe outcomes will be measured using several bribe elicitation strategies discussed at length in Reid and Weigel (2017). We will also collect solicited bribes, defined as a binary outcome for whether a tax collector solicited a bribe from an individual property owner, on the smaller endline sample to measure the prevalence of solicitations compared to bribe payments.
} 


\subsection{Treatment Effect Heterogeneity: Subgroup Analysis}

We hypothesize that the elasticity of tax compliance may vary by the following subgroups:

\section{Characteristics of property and owner}

- Age of property owner: We expect the elasticity to vary with the age of the property owner but that the predicted effect is ambiguous - older owners may be more willing to pay at lower rates, given they are more likely to be aware of past rates, which may make the elasticity higher due to transaction value, but these owners may also have more exposure to the enforcement environment, which, if they understand it to be low, may make the elasticity lower.

- Gender of property owner: Gender differences may impact the bargaining relationship with the tax collector over payment, given differences in gender roles in our context, but the hypothesized effect is ambiguous.

- Education of property owner: We expect a lower elasticity among more educated owners as they are more likely to be aware that the enforcement capacity of the government to punish non-payers is low.

- Tribe and sub-tribe of property owner (and whether these characteristics match with that of the collector, to assess how bargaining or bribes may vary along this dimension): We expect a lower elasticity among households where the collector's ethnicity matches the property owner's ethnicity because the payer feels a stronger obligation to pay regardless of the rate.

- Views and beliefs about government (measured by reported views on performance of state and state agents at baseline): We expect a lower elasticity among those with more positive views of the state, as they are more likely to pay regardless of the amount, and civic motivations may override differences in the likelihood of payment at lower or higher rates.

- Income/cash on hand of property owner (measured by reported earnings and reported expenditures on transport and phone credit): We expect a larger elasticity among liquidity constrained individuals.

- Government connections of property owner (including whether a family member works for the government as a measure of the perceived legitimacy of the government): We expect lower elasticity among those connected to the government as these owners may feel more intrinsically motivated to pay regardless of the rate.

- Quality of property and buildings (material and condition of walls, roof, buildings as measured by surveys and photos of households, erosion of street): Here we can compute the assigned liability with respect to the estimated value of the house. We expect this elasticity to be larger than the elasticity estimated without regard to house quality as it will incorporate greater variation in household value into the determination of the elasticity, meaning 
smaller changes in the official property-value-adjusted rate may yield greater changes in compliance.

2. Timing of taxation during month (date of tax collector visits in relation to measures of cash-onhand given timing of government salary payments, school fee payments, and other time-varying shocks to liquidity): We expect a lower elasticity early in the month right after pay day when liquidity constraints are less likely to bind.

\section{Past tax payment status}

- Past tax payment in 2016 of property owner (defined as whether an owner paid in 2016 and whether their neighborhood was taxed in 2016): We expect a lower elasticity because of higher views about enforcement among past payers (those exposed to taxation) as well as the possibility of habit formation. We expect a lower elasticity in neighborhoods taxed in 2016 compared to those untaxed in 2016 due to stronger beliefs about enforcement in areas that have been previously taxed.

- Share of property owner's neighbors making past tax payment in 2016 (defined as share of neighbors making payments in 2016): We expect a lower elasticity in neighborhoods where more neighbors' paid in 2016 due to stronger beliefs about enforcement or compliance norms in these areas.

\section{Neighbors' tax rates}

- Neighbors' actual assigned rates (defined as those assigned to surrounding households which can be identified by the census survey locations and geographic data on household locations): We expect awareness of higher rates to decrease the likelihood of payment due to feelings of unfairness, and we expect awareness of lower rates to increase the likelihood of payment due to perceived transaction value. Actual assigned rates will be a proxy for awareness.

- Awareness of neighbors' rates (measured after taxation campaign, defined as awareness of property owner of rate neighbors received or whether neighbors received lower or higher rates): We expect the same heterogeneity in the elasticity as in response to neighbors' actual tax rates. Awareness of those rates may make these differences more pronounced, as compared to the random assignment alone, because we expect to be positively but not perfectly correlated with awareness.

- Neighbors' compliance rate (measured as whether neighboring households also paid/did not pay the property tax): How neighbors' compliance affects the elasticity is ambiguous as it depends on at what rate neighbors are paying and whether property owners are aware of those rates. For example, knowing that many neighbors paid and being aware of those rates, may make the elasticity higher due to perceived unfairness; knowing that many neighbors 
did not pay at low rates may make the elasticity lower as those facing higher rates may be more likely to pay if they feel they were correctly assigned a higher rate, and that the enforcement likelihood is greater at higher rates.

- Awareness of neighbors' compliance rate (measured as whether property owners are aware that neighboring households also paid/did not pay the property tax, and at which rates): Same ambiguous prediction as for neighbors' true rate.

5. Awareness of receiving a discount (measured after taxation campaign, defined as awareness of true rate and whether property owner realizes that he or she received a discounted rate $)^{11}$ : We expect awareness of lower rates to increase the likelihood of payment due to perceived transaction value.

6. Receipt on tax bill (whether tax bill contains a picture of tax receipt or not, randomized at tax bill distribution, used to capture variation in awareness of receipt requirement in collection which may affect whether owners ask for and collectors provide receipts, as a measure of collector corruption): We expect a higher elasticity when the receipt is included in the tax bill because paying bribes may be perceived as more costly.

7. Messages on tax bills (these are randomly assigned messages as part of the Balán, Bergeron, Tourek, and Weigel (2018) study, which communicate information about trust, public goods, and sanctions): The predicted effect is ambiguous. Depending on whether the elasticity is driven by tax morale, enforcement, or beliefs about public goods provision, these messages may activate compliance at lower or higher rates differentially. We will use these messages to help understand what drives compliance across rates.

8. Collector characteristics (including ethnicity, gender, age, whether DGRKOC agent or chief, if chief: whether collected in the past, how long served as chief, quality of performance as chief): We expect the elasticity to vary with collector characteristics. The predicted effect of collector characteristics — which may combine multiple characteristics — is ambiguous, but relevant to considering the optimal design of collection methods. We will not focus on this aspect of the study in this document, as the hypotheses (around the effectiveness of collectors), data collection, and estimation approaches have already been described in the pre-analysis plan for Weigel (2018).

\footnotetext{
${ }^{11}$ This measure to address a concern that owners may respond to lower rates because of a 'discount effect', and choose to pay because they view the lower rate as an opportunity to lower their true tax burden relative to the status quo level. We believe this is not a strong concern as the tax rate changes normally year-to-year with inflation and taxpayers are likely not aware of the fixed full rate at the time of our campaign.
} 


\section{Evaluation Design}

\subsection{Sampling and Identification Strategy}

The unit of randomization is the property. Randomization of tax rates is conducted at the individuallevel within neighborhoods, or polygons, which we define on a satellite map using boundaries like roads, ravines, or other natural features that would be easily identifiable from the ground (see Figure 2). There are 356 neighborhoods in the full sample, containing approximately 46,000 individual periphery or midrange properties. ${ }^{12}$

The randomization is conducted ex ante by assigning rates to property codes that are then assigned sequentially as part of the door-to-door collection campaign. Teams of collectors and an enumerator start in the northeast corner of a polygon and proceed down avenues assigning codes to each individual property, writing these in chalk on the side of a property building or wall. At the time of the code assignment, property owners are given the tax bill that contains their code and assigned rate.

Figure 2: The unit of randomization - neighborhoods of Kananga

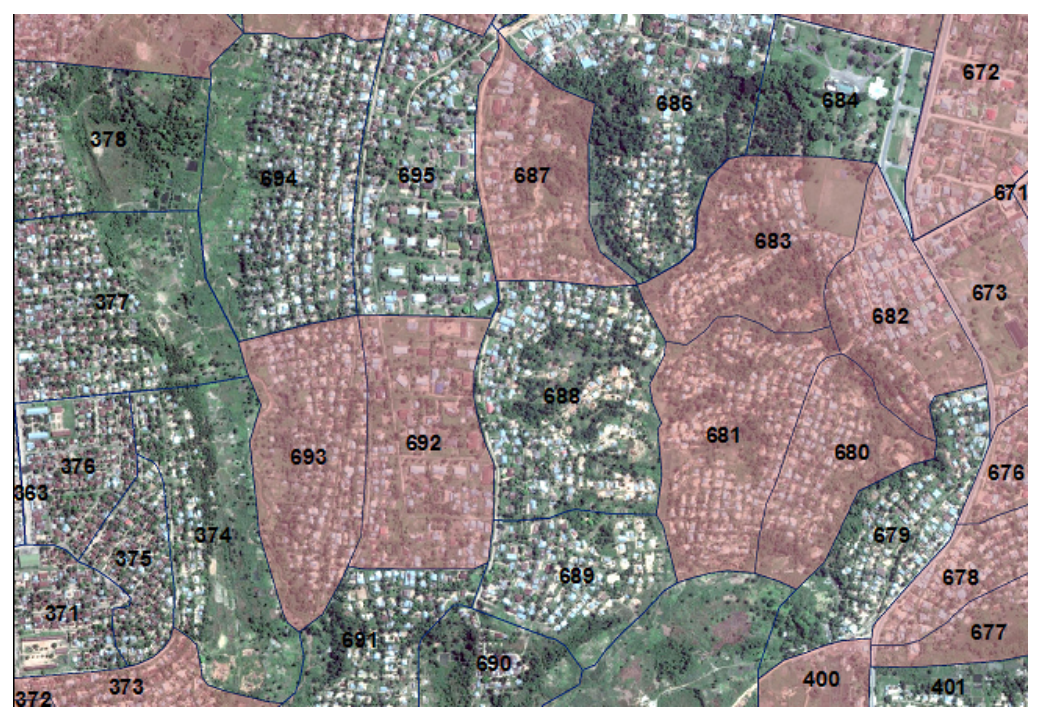

Table 3 shows the expected assignment of households to tax rates based on estimates from Weigel (2018) of the proportion of periphery to midrange properties in Kananga. ${ }^{13}$

\footnotetext{
${ }^{12}$ We exclude the commune of Nganza, to the south of the city, where in 2017 violence led a majority of the population of Nganza to move elsewhere in the city. When designing the tax campaign, the government decided that it would be too difficult to do tax collection in this commune. We also exclude neighborhoods that were part of a pilot experiment conducted as part of Balán, Bergeron, Tourek, and Weigel (2018).

${ }^{13}$ This allocation also assumes that the rate of collection during the census survey described in Section 6.3 does not differ from post-census collections. If collections are higher (lower) during the census, then we expect proportionally more of the total sample to fall within the Constant Bonus (30\% Bonus) group as collections during the census are automatically assigned a constant bonus.
} 
Table 3: Treatment allocation

\begin{tabular}{lccccc}
\hline & & \multicolumn{4}{c}{ Rate Treatment (\% Full Rate) } \\
\cline { 3 - 6 } & & $\mathbf{5 0 \%}$ & $\mathbf{6 6 \%}$ & $\mathbf{8 8 \%}$ & $\mathbf{1 0 0 \%}$ \\
\hline $30 \%$ Bonus & Periphery & 5,175 & 5,175 & 5,175 & 5,175 \\
& Midrange & 575 & 575 & 575 & 575 \\
Constant Bonus & Periphery & 5,175 & 5,175 & 5,175 & 5,175 \\
& Midrange & 575 & 575 & 575 & 575 \\
\hline
\end{tabular}

\subsection{Stages of Implementation}

The taxation campaign consists of two stages: census and taxation. Each polygon will be taxed for a period of approximately 4 weeks. ${ }^{14}$

Before the start of the campaign, collectors participate in training sessions, conducted at the tax ministry, during which they learn property tax campaign rules and protocols (rates, exemptions, etc). Collectors also learn how to use the handheld receipt printers they use in recording tax payments.

The first step of the campaign is the creation of an up-to-date register of all property owners living in the neighborhood. We refer to this as the 'census' for brevity. A register is taken in all neighborhoods (including the five control neighborhoods of Balán, Bergeron, Tourek, and Weigel (2018) where no collectors do door-to-door collections visits). Teams of tax collectors visit every house in a given neighborhood, accompanied by independent enumerators (who work for the research team rather than the government) trained to use tablets with GPS capabilities. The register visit serves three purposes. First, citizens are informed about the campaign. Second, houses are assigned a unique code and are given the tax bill containing the tax rate. The codes enable collectors to return to the neighborhood alone knowing its boundaries based on the codes, which begin with the first digits of the neighborhood. This effectively produces a cadastral map of the city. Finally, enumerators fill out a short survey recording details about the transaction that we will use in the analysis.

Upon completion of the property register, tax collectors begin collection, which lasts for the rest each tax period. During taxation, enumerators no longer accompany tax collectors.

\footnotetext{
${ }^{14}$ Taxation periods for individual polygons at the end of the campaign may be shortened slightly depending on the timing of an election in 2018, which could create demands on the time of government officials that might disrupt the taxation campaign.
} 
Table 4: Campaign stages

\begin{tabular}{llcc}
\hline Stage & Period & Collectors & Enumerators \\
\hline Stage 1: Census & First days of 4 week period & Yes & Yes \\
Stage 2: Tax collection & Rest of 4 week period & Yes & No \\
\hline
\end{tabular}

In all treatment arms citizens can pay either during the census visit or during subsequent tax visits. Collectors bring the money to the provincial tax ministry. Collectors are equipped with hand-held receipt printers to issue receipts for the taxpayers. Two receipts are automatically printed in the field, one for the taxpayer and one for the collector. Collectors bring the money to the provincial tax ministry, account for the money they deposit, and need to justify any discrepancy between the total sum on their report and the money they have with them. The receipt printer also stores all transactions in its memory, which forms the basis of the administrative data.

Importantly, collectors can also tax households during the census. This has the advantage of holding constant targeting of specific types of households by collectors, since at this stage collectors are forced to visit every household in a sequential order that is supervised by the enumerator (and can be confirmed using GPS data collected during census visits). Moreover, because of the census survey (discussed in the next section), we observe key details about tax transactions that occur during this first visit of the tax collector, which allows us to test a range of hypotheses about why citizens pay the property tax. The tax collection campaign will run for just over six months.

\section{Data Collection}

\subsection{Respondent baseline survey}

We administered surveys at baseline to 4,343 randomly selected households - approximately 12 per neighborhood. ${ }^{15}$ Randomization was achieved by having enumerators visit every $X$ th house, where $X$ is determined by the estimated number of houses in the neighborhood to yield 12 surveys per neighborhood. The baseline survey instrument covers a range of topics, including but not limited to: demographics, property characteristics, views of government, access to public goods, experience with taxation and (formal and informal) payments to the state, property taxes, rental taxes, city chiefs, political beliefs and participation, and social networks.

\footnotetext{
${ }^{15}$ The total number is a not a multiple of twelve as it was not possible to identify 12 respondents in some small neighborhoods.
} 


\subsection{Collector survey}

This survey measures characteristics of collectors. All collectors who work on the campaign - be they tax ministry agents, chiefs or their assistants - participate in this survey. It includes a reading and a typing test, questions on their experience collecting taxes and working for the tax ministry, beliefs about taxation, preferences for redistribution, public goods, state capacity, trust in different institutions, tax morale, and perceived willingness of citizens to pay the property tax under different hypothetical tax rates. This survey is administered before and after taxation.

\subsection{Census survey}

This survey is completed by members of the research team while the tax collectors construct the property register (census). It records the code that is assigned to each household, its geographic coordinates, the name of the property owner, the property tax rate faced by each household (assigned on the spot during the census), and whether a household is exempt from the property tax. ${ }^{16}$ It also contains the protocol collectors read informing respondents about the tax campaign.

\subsection{Midline survey}

This survey is administered to every household in the city by enumerators after tax collection is finished in a neighborhood. Its goal is to measure certain short-term outcomes and covariates for the universe of potential taxpayers. The midline survey covers a range of topics, including but not limited to: whether a household was visited by tax collectors, the number of times it was visited, whether it paid the property tax, whether the respondent was given a receipt, the reasons why the respondent paid taxes, whether the respondent is aware of the rates collectors asked at other households, whether the household head and the tax collectors knew each other previously, and whether tax collectors asked respondents for bribes during the campaign.

\subsection{Respondent endline survey}

This survey will be conducted after the campaign and contains questions about tax compliance and morale, the perceived fairness of different modes of tax collection, property-related disputes, attitudes towards the state, beliefs about the government and chiefs, engagement with the government and chiefs, use of formal and informal sectors, and other outcomes of interest. Enumerators will revisit the randomly chosen sample of respondents for the baseline survey and potentially a set of new randomly sampled households.

\footnotetext{
${ }^{16}$ The following cases are exempt from the property tax: (1) state-owned properties, (2) schools, churches, and scientific or philanthropic institutions, (3) houses owned by the elderly (55 years or above), widows or disabled people, (4) houses in construction or owned by international organizations.
} 


\subsection{Administrative data}

The handheld receipt printers store each receipt in their memory. This generates administrative data used by the government to track progress in the tax campaign. The printers collect the collector's name and ID number, date and time stamps, neighborhood number, the house category and identification number, the tax rate, and the amount paid. We will use these data, linked to household surveys using the ID number, as a measure of tax compliance.

\section{Power analysis}

As noted, the primary outcome is tax compliance: that is, the percentage of individuals who pay in the different tax-rate treatment groups. This outcome will be calculated using taxpayer-level administrative data from the tax ministry. ${ }^{17}$ A secondary outcome is bribe taking: the percentage of individuals who bribed the tax collector in the different tax-rate treatment groups.

Simple power calculations were conducted using data from the 2016 property tax campaign. According to Stata's power command, we would need a sample of 838 individuals per tax-rate arm to detect an effect of 0.2 standard deviations (about 5 percentage points) on the mean from neighborhoods visited by tax collectors in 2016. Our projected sample size of 11,500 individuals per tax-rate arm allows us to detect effects of less than 0.1 standard deviations (less than 2.5 percentage points).

\section{Econometric Specifications and Proposed Analyses}

\subsection{Basic Specifications}

We will estimate effects using an intent-to-treat framework. For outcomes $Y_{i p}$, where $i$ indexes the individual and $p$ indexes the polygon (neighborhood), we will run the following regression:

$$
y_{i p}=\beta_{0}+\beta_{1} R A T E 50_{i p}+\beta_{2} R A T E 66_{i p}+\beta_{3} R A T E 88_{i p}+X_{i p}^{\prime} \delta+\eta_{p}+\epsilon_{i p}
$$

where $R A T E 50_{i p}$ is an indicator for individuals who receive a $50 \%$ rate, and likewise for the $66 \%$ and $88 \%$ treatments. The excluded category is the normal rate rate. $X_{i p}$ is a vector of individual controls, which will be collected during initial pre-treatment surveys, and include fixed effects for the type of property. We will include a polygon fixed effect $\eta_{p}$. We will estimate robust standard errors but will

\footnotetext{
${ }^{17}$ In rare cases of data loss due to discharged batteries, we can also combine the administrative data on compliance with data collected during the midline survey on the presence of a valid receipt from 2018. These receipts are very difficult to forge, so the union of (a) admin data, (b) presence of a receipt at midline will likely be our best ultimate measure of tax payment.
} 
not cluster by polygon, partly because the fixed effects account for within polygon correlations across property owners in mean outcomes. We will estimate this equation pooling periphery and midrange properties and separately by property type.

\subsection{Treatment Effect Heterogeneity}

We will estimate treatment effect heterogeneity with the following equation:

$$
\begin{array}{r}
y_{i p}=\beta_{0}+\beta_{1} R A T E 50_{i p}+\beta_{2} R A T E 66_{i p}+\beta_{3} R A T E 88_{i p} \\
+\beta_{4}^{\prime}\left(R A T E 50_{i p} \times Z_{i p}\right)+\beta_{5}^{\prime}\left(R A T E 66_{i p} \times Z_{i p}\right)+\beta_{6}^{\prime}\left(R A T E 88_{i p} \times Z_{i p}\right) \\
+\gamma Z_{i p}+\eta_{p}+X_{i p}^{\prime} \delta+\epsilon_{i p}
\end{array}
$$

where $Z_{i p}$ is a measure described in Section 4.2. ${ }^{18}$

\subsection{Samples and Covariates}

There are two main sets of analysis we will run.

1. Analysis using the universe of taxpayers. For our primary outcome of tax payments we will use administrative data to evaluate the effect of the various treatment arms on compliance. For this analysis, we have the universe of compounds in Kananga, approximately 46,000 according to data from Weigel (2018). For individual covariates, we can use household-level variables collected during the census survey and during the midline survey. In our estimation, we will include one specification with no covariates and additional specifications with the following covariates:

- Individual-level covariates: A dummy indicating whether a household paid the property tax in the past, an index of estimated household wealth (an index constructed from household observables, such as roof type, building materials, and condition of the fence), a dummy variable for government workers, including avenue and locality chiefs, age, age squared, and gender.

- Neighborhood-level covariates: Distance to city center, population, and past average tax compliance.

In addition, we will test for balance across a larger set of individual- and neighborhoodlevel variables and we will show robustness to controlling for any that are significantly imbalanced.

\footnotetext{
${ }^{18}$ Some measures of heterogeneity, like access to public goods or tax collector type, will vary at the polygon-level. In these specifications, $Z_{p}$ will replace $Z_{i p}$ in the regression, and we will remove polygon fixed effects.
} 
2. Analysis using endline survey sample. For outcomes not included in the administrative data or in surveys administered to every household in Kananga, we will rely on an endline survey. Our estimated endline sample size will be at least as large as our baseline sample $(\mathrm{N}=4,343)$. Our estimation approach will be similar to that noted above, except that we will have a larger set of possible individual-level covariates.

\subsection{Controlling for Collector Effort}

To control for the potential bias introduced by collector effort, we will employ several strategies:

1. Restricting sample to census collections: Census tax collections hold constant both the bonus received by the collector (fixed at $750 \mathrm{CF}$ ) and the potential targeting of certain households by tax collectors (because households are visited in a sequential order, verified by a member of the research team). We will estimate our primary specifications separately on this subgroup.

2. Holding constant number of visits by collectors: To account for effort in the targeting of households by tax collectors, we will control for the number of visits collectors made. Note that more visits indicates a higher degree of effort expended by the collector to tax a household. We can measure this (a) using self-reports of visits by property owners in the midline survey, (b) using dates written on the wall in chalk by the collectors each time they visit a house. ${ }^{19}$ Self-reported visits by households may not capture targeting perfectly - e.g., households that pay immediately may have been targeted but because of their early complier status would be coded as receiving fewer visits and thus less targeting per this definition. To address this concern we will also estimate specifications that simultaneously include controls for census collections and the date of tax payment during the taxation period for a specific polygon.

3. Estimating effects separately by bonus group: To assess how the form of the bonus - fixed or proportional - affects the estimated effects, we will estimate the specifications separately by each bonus group.

4. Controlling for bonus amount: Rather than estimating separate effects by bonus groups, we will pool the sample and additionally control for the bonus amount assigned to an individual property.

\subsection{Assessing Spillovers}

There is a concern that individual property owners will become aware that their neighbors are paying different rates, which may bias estimation of a pure elasticity with respect to the tax rate if the decision to pay (or offer bribes) is additionally affected by perceptions of fairness around one's assigned rate.

\footnotetext{
${ }^{19}$ In practice, it is uncertain whether collectors will sufficiently comply with this procedure of writing the date on the wall for each visit. We will assess the viability of this strategy after data collection to determine if it is reliable.
} 
Alternatively, awareness of neighbors with higher rates could lead individuals to believe they are getting a 'deal,' i.e. generate transaction utility (Thaler, 1985), and similarly create upward bias on our estimate of the effect of a lower tax rate on compliance. To address possible spillovers, we have five strategies.

First, in the midline survey, we will collect measures of individuals' awareness of others' rates (the actual rate of neighbors and whether neighbors had lower or higher rates) to identify individuals with this knowledge. We will then estimate the effects of individual tax rates excluding this group or including in the regression on the full sample an indicator for whether a property owner possesses this knowledge.

Second, we can leverage random geographic variation in the rates assigned to neighbors to assess how having more neighbors with lower or higher rates relative to one's own affects the probability of payment. Due to the random assignment of rates, some properties will be surrounded by neighbors with similar rates while others will be surrounded by neighbors with different rates (conditional on property type). This should permit us to estimate the elasticity separately for individuals whose neighbors are paying the same rate, and compare this to the analogous elasticity estimate among households whose neighbors pay different rates.

Third, we can estimate the spillover directly following the methodology of (Miguel and Kremer, 2004). Because we have random variation in the number of neighbors who pay higher rates (and lower rates), we can estimate spillovers on compliance decisions.

Fourth, we collect in the midline survey whether individuals had heard of anyone receiving a discount on the property tax this year and whether they themselves received a discount. We can again run our analysis in the subgroup that had heard nothing of discounts and compare this to the subgroup that had heard of them to see if transaction utility or a sense of unfairness could be biasing our estimated elasticities. Alternatively, we can control for this awareness in the main specification.

Fifth, we can control directly for neighbors' tax rates. We observe the geographic location of households and can control for households next door or within a defined geographic distance from an individual household.

\subsection{Cash-on-Hand Effects}

As payment ability may be affected by credit constraints at the time of taxation, we will assess how compliance varies across the month. In Kananga, where the government employs a large share of the population, payments to government employees are made on specific dates. Anecdotally, these payments are often disseminated through family and social networks, meaning cash-on-hand for government workers and those in their networks may be higher after salaries are paid. Using the dates of these payments and comparing them to the dates of taxation, we will assess whether cash-on-hand affects the likelihood of property tax payment. We will also conduct this analysis on a sample that excludes government workers themselves, so the shock to liquidity would stem from family redistribu- 
tion networks. Comparing time variation in tax payments among government workers, or individuals connected to government workers, to individuals not connected to government or government workers could provide a method for causally identifying the impact of cash-on-hand. ${ }^{20}$

\subsection{Accounting for House Value}

Because the tax rates are randomly assigned, the analysis does not need to calculate liability relative to house value. However, doing so in an extension will connect our analysis to property tax systems in which the property valuation is utilized. The analysis would be similar, but we would operationalize a continuous tax liability independent variable constructed by dividing the assigned rate by the estimated value of the house.

To estimate house values, we will use a subsample of houses for which we observe the price at which the house was sold. We can use this sample to train a machine-learning algorithm using survey measures about house quality (walls, roof, fence, etc) and photo data of each house (as well as satellite data to estimate plot size), and thus estimate house value for all houses in the sample. Tasks such as automatically classifying and labeling images are now much easier, thanks in part to the availability of more comprehensive training datasets and new machine learning algorithms (Naik, Philippom, Raskar, and Hidalgo, 2014; Naik, Kominers, Raskar, Glaeser, and Hidalgo, 2017).

\subsection{Heterogeneous Treatment Effects}

Following Chernozhukov, Duflo, Demirer, and Fernandez-Val (2018), we will use machine learning methods to measure heterogeneous treatment effects. ${ }^{21}$ The wealth of data we have on individual households, including detailed survey measures and variables associated with properties, permits application of these methods to potentially identify marginal compliers, which may permit simulation of the revenue gains of different tax rates and collection strategies.

\subsection{Instrumental Variables Specifications}

Although all households are assigned specific rates, collector non-compliance, error, or bargaining and bribe processes between collectors and households mean that households may not pay the rate they were assigned.

To account for this issue, we will conduct an instrumental variables estimation of the effect of the

\footnotetext{
${ }^{20}$ At this stage, we are still in the process of obtaining government payment records to identify dates of payment and collecting measures of connections to government workers to determine which empirical approaches may be viable, and therefore we do not pre-specify a precise empirical strategy.

${ }^{21}$ These include best linear predictors of impacts using machine learning proxies, average treatments effects sorted by impact groups, and average characteristics of most and least impacted units (Chernozhukov, Duflo, Demirer, and FernandezVal, 2018).
} 
rate treatments using the rate the household paid as the endogenous variable and their assigned rate as the instrument. In the census survey, we observe what rate was assigned and in the taxation data we will observe the amount the household actually paid. There will be first-stage equations for each rate, and we will employ a two-stage least squares estimation strategy.

\section{Timeline}

Figure 3 shows a timeline of the campaign. A first pilot in 4 neighborhoods was conducted in MarchApril 2018. The property tax campaign started on 15 June and will last for a just over 6 months. Given the number of neighborhoods and collectors involves, the tax campaign will be staggered across neighborhoods.

Figure 3: Timeline

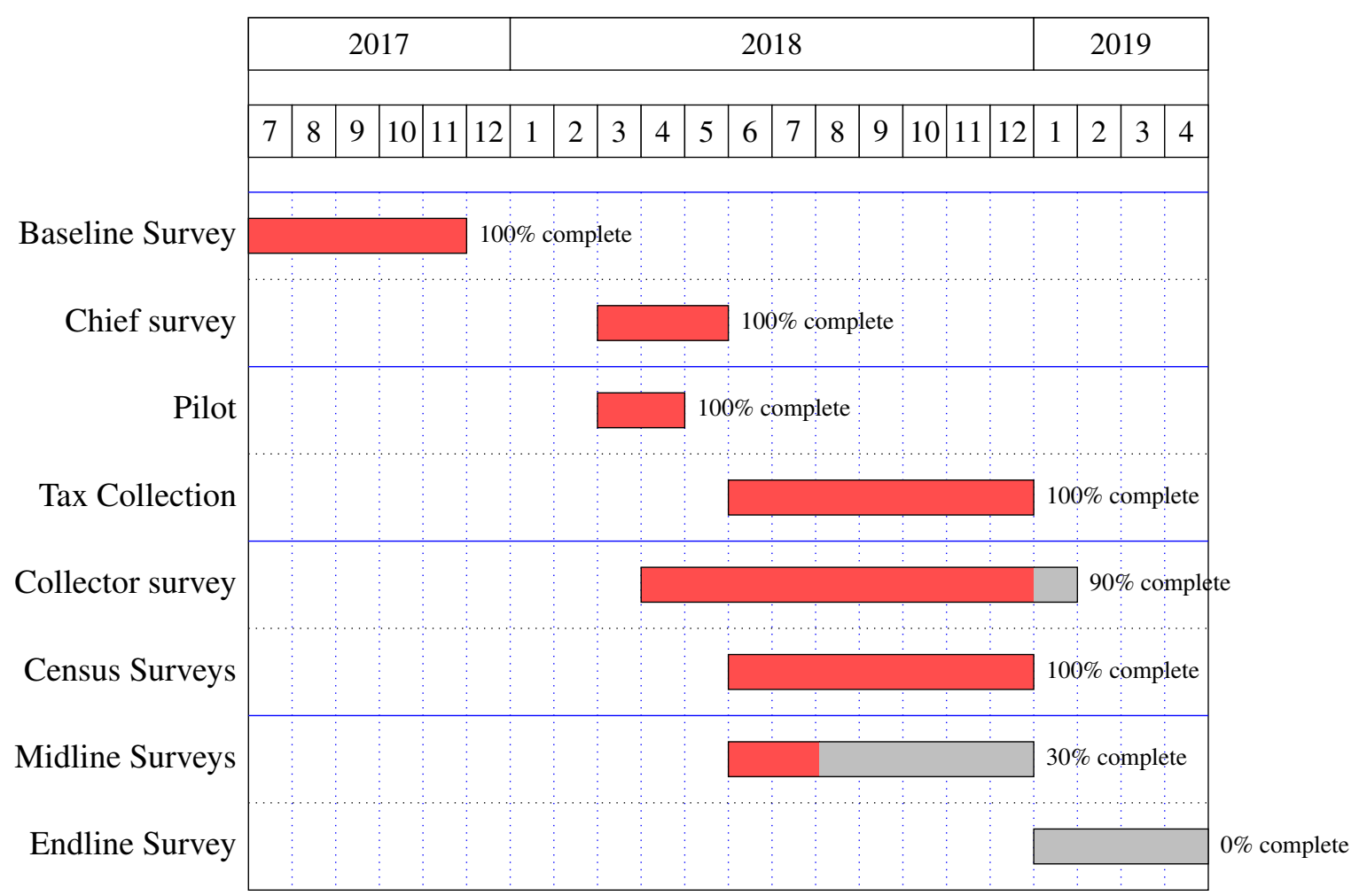




\section{References}

Ashenfelter, O., and M. Plant (1990): "Nonparametric Estimates of the Labor-Supply Effects of Negative Income Tax Programs," Journal of Labor Economics, 8(1), S386-415.

Balán, P., A. Bergeron, G. Tourek, and J. Weigel (2018): “The Origins of Accountable Governance: Experimental Evidence from the DRC," .

Bergolo, M., R. Ceni, G. Cruces, M. Giaccobasso, and R. Perez-Truglia (2018): "Misperceptions About Tax Audits," American Economic Association Papers and Proceedings, 108(May 2018), 83-87.

Besley, T., And T. Persson (2009): “The Origins of State Capacity: Property Rights, Taxation and Politics," American Economic Review, 99(4), 1218-1244.

Blumenthal, M., C. Christian, J. Slemrod, and M. G. Smith (2001): "Do Normative Appeals Affect Tax Compliance? Evidence From a Controlled Experiment in Minnesota," National Tax Journal, pp. 125-138.

Chernozhukov, V., E. Duflo, M. Demirer, and I. Fernandez-Val (2018): “Generic Machine Learning Inference on Heterogeneous Treatment Effects in Randomized Experiments," Working Paper.

Chetty, R., A. Guren, D. Manoli, and A. Weber (2013): "Does Indivisible Labor Explain the Difference Between Micro and Macro Elasticities? A Meta-Analysis of Extensive Margin Elasticities," NBER Macroeconomics Annual 2012, 27, 1-56.

Del Carpio, L. (2013): "Are the neighbors cheating? Evidence from a social norm experiment on property taxes in Peru," Princeton University Working Paper.

Dunning, T., F. Monestier, R. Piñeiro, F. Rosenblatt, and G. Tuñón (2015): "Positive Vs. Negative Incentives for Compliance: Evaluating a Randomized Tax Holiday in Uruguay," Working Paper.

Eissa, N., And J. Liebman (1996): "Labor Supply Response to the Earned Income Tax Credit," Quarterly Journal of Economics, 111(2), 605-637.

Fellner, G., R. Sausgruber, and C. Traxler (2013): "Testing enforcement strategies in the field: Threat, moral appeal and social information," Journal of the European Economic Association, 11(3), 634-660.

Hallsworth, M., J. A. List, R. D. Metcalfe, and I. Vlaev (2017): "The Behavioralist as Tax Collector: Using Natural Field Experiments to Enhance Tax Compliance," Journal of Public Economics, 148, 14-31. 
Huntington, S. (2006): Political order in changing societies. Yale University Press.

KALDOR, N. (1963): Foreign Affairs41(2), 410-419.

Levi, M. (1988): Of Rule and Revenue. University of California Press.

Miguel, E., And M. Kremer (2004): "Worms: identifying impacts on education and health in the presence of treatment externalities," Econometrica, 72(1), 159-217.

Moore, M. (2008): Between coercion and contract: competing narratives on taxation and governance.

Naik, N., S. D. Kominers, R. Raskar, E. Glaeser, and C. Hidalgo (2017): “Computer vision uncovers predictors of physical urban change," PNAS, 114(29), 7571-7576.

NAIK, N., J. PhILIPPOM, R. RASKAR, AND C. HidAlgo (2014): "Computer vision uncovers predictors of physical urban change," Proceedings of the 2014 IEEE Conference on Computer Vision and Pattern Recognition Workshops (IEEE, Washington, DC), pp. 793-799.

Olken, B., And M. Singhal (2011): "Informal Taxation," American Economic Journal: Applied Economics, 3(4), 1-28.

Pomeranz, D. (2015): "No Taxation Without Information: Deterrence and Self-Enforcement in the Value Added Tax," The American Economic Review, 105(8), 2539-2569.

PRITCHARD, W. (2015): Taxation, responsiveness and accountability in Sub-Saharan Africa: the dynamics of tax bargaining. Cambridge University Press.

ReID, O., And J. WeIgel (2017): “Citizen Participation in Corruption: Evidence from Roadway Tolls in the Democratic Republic of the Congo," Working Paper.

SAEZ, E. (2010): “Do Taxpayer Bunch at Kink Points?," American Economic Journal: Economic Policy, 2(3), 180-212.

Saez, E., J. Slemrod, And S. Giertz (2012): "The Elasticity of Taxable Income with Respect to Marginal Tax Rates: A Critical Review," Journal of Economic Literature, 50, 3-50.

SChumpeter, J. (1918): “The crisis of the tax state," International Economic Papers, 4, 5-38.

Sequeira, S. (2016): "Corruption, Trade Costs, and Gains from Tariff Liberalization: Evidence from Southern Africa," The American Economic Review, 106(10), 3029-3063.

THALER, R. (1985): “Mental accounting and consumer choice,” Marketing science, 4(3), 199-214.

Weigel, J. (2018): "The Taxman Cometh: A Virtuous Cycle of Compliance and State Legitimacy in the D.R. Congo," Working Paper. 